\title{
Association between tax structure and cigarette consumption: findings from the International Tobacco Control Policy Evaluation (ITC) Project
}

\author{
Ce Shang, ${ }^{1}$ Hye Myung Lee, ${ }^{2}$ Frank J Chaloupka, ${ }^{1,2}$ Geoffrey T Fong, ${ }^{3,4}$ \\ Mary Thompson, ${ }^{5}$ Richard J O'Connor ${ }^{6}$
}

\begin{abstract}
- Additional material is published online only. To view please visit the journal online (http://dx.doi.org/10.1136/ tobaccocontrol-2017-054160).
\end{abstract}

${ }^{1}$ Health Policy Center, Institute for Health Research and Policy, University of Illinois at Chicago, Chicago, Illinois, USA

${ }^{2}$ Division of Health Policy and Administration, School of Public Health, University of Illinois at Chicago, Chicago, Illinois, USA ${ }^{3}$ Department of Psychology, University of Waterloo, Waterloo, Ontario, Canada

${ }^{4}$ Ontario Institute for Cancer Research, Toronto, Ontario,

Canada

${ }^{5}$ Department of Statistics and Actuarial Science, University of Waterloo, Waterloo, Ontario, Canada

${ }^{6}$ Division of Cancer Prevention and Population Sciences, Department of Health Behavior, Roswell Park Cancer Institute, Buffalo, New York, USA

\section{Correspondence to}

Dr Ce Shang, Health Policy Center, Institute for Health Research and Policy, University of Illinois at Chicago, Chicago, IL 60607, USA; cshang@uic.edu

Received 17 November 2018 Revised 19 February 2018 Accepted 3 May 2018

Published Online First 24 May 2018

Check for updates

To cite: Shang C, Lee HM,

Chaloupka FJ, et al.

Tob Control

2019:28:s31-s36.

\section{ABSTRACT}

Background Recent studies show that greater price variability and more opportunities for tax avoidance are associated with tax structures that depart from a specific uniform one. These findings indicate that tax structures other than a specific uniform one may lead to more cigarette consumption.

Objective This paper aims to examine how cigarette tax structure is associated with cigarette consumption. Methods We used survey data taken from the International Tobacco Control Policy Evaluation Project in 17 countries to conduct the analysis. Self-reported cigarette consumption was aggregated to average measures for each surveyed country and wave. The effect of tax structures on cigarette consumption was estimated using generalised estimating equations after adjusting for sociodemographic characteristics, average taxes and year fixed effects.

Findings Our study provides important empirical evidence of a relationship between tax structure and cigarette consumption. We find that a change from a specific to an ad valorem structure is associated with a $6 \%-11 \%$ higher cigarette consumption. In addition, a change from uniform to tiered structure is associated with a 34\%-65\% higher cigarette consumption. The results are consistent with existing evidence and suggest that a uniform and specific tax structure is the most effective tax structure for reducing tobacco consumption.

\section{INTRODUCTION}

Raising excise taxes on tobacco products is the most effective tobacco control strategy among the policies advocated by the WHO Framework Convention on Tobacco Control (FCTC). ${ }^{1}$ However, the effectiveness of increasing excise taxes as a tobacco control means depends on the tax structure, that is, on what basis taxes are levied (quantity vs value vs both) and how tax rates are determined (a single rate vs multiple rates). ${ }^{2-5}$ There are in total six different types of tax structures: specific uniform (quantity based, a single rate), specific tiered (quantity based, multiple rates), ad valorem uniform (value based, a single rate), ad valorem tiered (value based, multiple rates), mixed uniform (both quantity based and value based, single rates) and mixed tiered (both quantity based and value based, multiple rates). ${ }^{4}$

Among the six tax structure types, a specific uniform structure is the simplest from the tax administration perspective, because this system imposes one single tax rate based on quantities (eg, a $\$ 1.006667$ federal tax on a pack of 20 cigarettes in the USA). ${ }^{6}$ The rest of tax structures are more complicated because tax rates may significantly vary across different products. For example, when the bases are values or a mix of both values and quantities, each different product bears a different amount of taxes. In some counties, tax rates may further vary by different characteristics of the tobacco products (eg, length, price tiers, and so on, the examples of these tax structures can be found in the online supplementary appendix table). ${ }^{2}$ As a result, manufacturers could exploit a complicated tax structure to their advantage by strategically bypassing taxes, setting prices or designing products. ${ }^{7}$ Tax structures that deviate from a uniform specific structure are associated with an lower average price and a greater price gap between higher and lower priced products, and thus with more opportunities for smokers to avoid taxes by switching to cheaper products as taxes increase. ${ }^{45}$

In recent years, a growing body of literature investigated how complicated tax structures-ad valorem, tiered and mixed-are associated with price distribution. ${ }^{2-58}$ A series of studies provided descriptive evidence, showing that price variability tends to be greater when tax structures deviate from a specific uniform one. ${ }^{23}$ One study further employed regression analyses to estimate that a $10 \%$ increase in the share of specific taxes among total excises is associated with $2.8 \%-4.3 \%$ lower price variability, whereas a tiered tax structure is associated with a $61 \%-147 \%$ increase in price variability. ${ }^{4}$ Another study employed data from European Union (EU) countries to demonstrate that more reliance on ad valorem taxes in a mixed tax structure is associated with a lower average price and greater price variability. ${ }^{5}$

Despite growing evidence documenting the association between complicated tax structures and the price distribution with a lower mean and greater price variablity, ${ }^{4}$ no studies have examined the association between tax structures and tobacco use behaviours to our knowledge. As a lower average price along with greater price variability reflects more tax avoidance opportunities, it implies that complicated tax structures may be associated with higher cigarette consumption as a result of less effective taxation policies.

The hypothesised association between complicated tax structures and higher cigarette consumption is also supported by the evidence that tax 
avoidance inhibits quitting or reduction in consumption. ${ }^{9}$ Smokers who seek to minimise prices paid for cigarettes (eg, buy in bulk) were found less likely to make quit attempts or cut down their cigarette consumption. ${ }^{9}$ One recent study shows that in Thailand where the tax structure is an ad valorem uniform one, consumers switched down from more expensive to less expensive cigarette brands in response to a tax increase. ${ }^{10}$ Therefore, complicated tax structures may lead to stagnant cigarette consumption through providing opportunities for smokers to avoid paying high taxes and maintain their consumption level.

This study used regression analyses to examine the relationship between tax structures and cigarette consumption and tested the hypothesis that complicated tax structures are associated with higher cigarette consumption. Results of this study add to the evidence on how tax structures moderate the effectiveness of tax policies in tobacco control and suggest tax structures that maximise the effects of increasing taxes in reducing smoking and related adverse consequences.

\section{DATA AND MEASURES \\ Cigarette consumption}

Cigarette consumption is measured as the logarithm form of the number of cigarettes smoked per day by an average smoker. Consumption data were obtained from surveys conducted by the International Tobacco Control Policy Evaluation Project (the ITC project). The ITC project comprises parallel longitudinal surveys of smokers and other tobacco users in many countries, with an objective to systematically evaluate the psychosocial and behavioural impact of tobacco control policies under the WHO FCTC. ${ }^{211}$ The longitudinal cohort survey, which is conducted through telephone, face-to-face and online interviews, provides data on self-reported cigarette consumption of the population over time. We used all waves of this survey from 2002 to 2013 in 17 countries, including ITC-4 (the USA, the UK, Australia and Canada), the Netherlands, Germany, France, Republic of Korea, Mexico, Brazil, Uruguay, Mauritius, India, Bangladesh, China, Thailand and Malaysia, in order to compare tobacco consumption by tax structure.

\section{Cigarette excise tax structures}

Detailed information on tax structure was collected from various sources for each country over time from multiple sources. The primary source is the Table 9.1.0 of the 2013 WHO Report on the Global Tobacco Epidemic, which provides a summary on the prices (per 20-cigarette pack) of the most popular brands and the share of ad valorem and/or specific tax in those prices. ${ }^{12}{ }^{13}$ Other sources include Excise Duty Tables by the European Commission, the WHO country reports, the Technical Manual on Tobacco Tax Administration, Global data's country reports and Euromonitor International's country reports. Details about tax structure information from these data sources were described in a previous study. ${ }^{4}$ Throughout the study period, two countries had changed their tax structures. Mexico switched from an ad valorem uniform to a mixed uniform structure in 2009 and Brazil changed from a specific tiered to a mixed tiered system in $2012 .^{4}$

Following one previous study, ${ }^{4}$ tax structure measures consist of a continuous measure of the percentage of ad valorem taxes among the total excise taxes and a dummy for a tiered structure. The continuous measure ranges from 0 to 100 , with 0 representing the specific structure, 100 representing the ad valorem structure and any number in-between representing a mixed structure. This continuous variable also measures the weights that a mixed structure puts on specific versus ad valorem taxes. Because excise taxes can also be imposed at the local level in India, USA and Canada, we further constructed an indicator for these countries and controlled for the existences of local taxes. We also constructed a dummy variable to control for the constraint that EU imposes on member countries to implement a mixed tax structure.

\section{Cigarette excise taxes}

We compiled annual excise taxes in 2010 dollars levied on a 20-cigarette pack using similar sources. Tax rates from 2008 to 2012 for countries other than the USA, Canada, Australia and EU countries were obtained from 2013 WHO report on the Global Tobacco Epidemics Table 9.1.0, imputed using the price of a 20-cigarette pack of the most popular brands and ad valorem and/or specific taxes as a per cent of the price of most popular brand. Cigarette excise tax rates for the USA, Canada, Australia and EU from 2002 onwards came from a variety of sources. For EU countries, the excise information came from the Excise Duty Tables constructed by the European Commission; for Australia, it came from the Australian Taxation Office; for the USA, it came from Tax Burden on Tobacco by Orzechowski and Walker and was inclusive of federal and average state excise taxes; for Canada, it came from Other Comparative Tax Rates published by Finance and Treasury Board and was a population-weighted average of the federal and provincial taxes. For other countries with data collection before 2008, the tax rate information came from the Euromonitor reports and WHO periodic reports on the global tobacco epidemic.

\section{Demographic characteristics}

Demographic characteristics at the country-year level came from World Bank's World Development Indicators database. The demographic characteristics adjusted for as confounders are gross domestic product (GDP) per capita in international dollars (income), the percentage of women among total population (gender), unemployment rate (economic condition) and the percentage of population aged 15 or over (age). We also constructed a dummy for high-income countries (HIC) versus low/middle-income countries (LMIC) using World Bank's income group classification. During study period, none of the countries changed their income group classification. Specifically, Australia, Canada, USA, UK, the Netherlands, France, Germany and South Korea were HICs. Malaysia, Thailand, Mexico, Uruguay, China, Mauritius, Brazil, Bangladesh and India were LMICs.

\section{METHODOLOGY Data linkage}

Cigarette consumption, tax structure measures, cigarettes excise taxes and sociodemographic characteristics were linked together using country and year identifiers. As described in a previous study, some of the ITC survey waves were conducted across two calendar years. ${ }^{4}$ In those cases, we randomly assigned the calendar year to the wave. Furthermore, in order to directly estimate the tax and income elasticities, cigarette consumption, excise taxes and GDP per capita are in log form.

\section{Modelling}

Following Shang et al (2016), ${ }^{4}$ we used generalised estimating equations (GEE) to examine the association between tax structures and cigarette consumption using an identity link, inversed Gaussian family and exchangeable correlation setting. GEE is a panel data technique that accounts for intertemporal 
correlations. The analyses were conducted using the XTGEE command in Stata SE V.14.1.

Tax structures have been shown to be associated with a lower average price and greater price variability. ${ }^{5}$ Therefore, we used different specifications to model the association between tax structures and cigarette consumption. First, we employed a reduced form approach by regressing cigarette consumption on tax structure measures and sociodemographic characteristics without controlling for average taxes. This is because tax structures may affect how taxes are passed to price and price distribution. Next, we modelled a more flexible approach by regressing consumption on average taxes and tax structures to examine the association between tax structures and consumption while holding average taxes constant. In addition, to adjust for the potential correlation between tax structure choices and countries' income groups (eg, tiered structures in the sample were only seen for LMICs), we controlled for a dummy for HICs $(\mathrm{LMICs}=0)$ for a sensitivity analysis. In total, four different specifications (with and without average taxes and with and without the HIC dummy as a confounder) were analysed after controlling for sociodemographic characteristics (age, gender, income and unemployment rate). Stratified analyses by HICs versus LMICs were also analysed because none of the HICs in the sample had a tiered structure. As a result, the analyses for HICs $(n=47)$ examined the association between the share of ad valorem taxes and cigarette consumption, whereas the analyses for LMICs $(n=31)$ examined the association between all types of tax structures (tiered and the share of ad valorem taxes) and cigarette consumption. Due to the sample size limitation, logistic regressions were used for the LMIC analyses to achieve a convergence.

\section{RESULTS}

In table 1 , we present an overview of the data and measures, including country names, tax structure types, share of ad valorem

\begin{tabular}{|c|c|c|c|c|}
\hline Country & Tax structure & $\begin{array}{l}\text { Share } \\
\text { of ad } \\
\text { valorem } \\
\text { tax }\end{array}$ & $\begin{array}{l}\text { Average } \\
\text { consumption } \\
\text { per day }\end{array}$ & $\begin{array}{l}\text { Number } \\
\text { of waves }\end{array}$ \\
\hline Australia & \multirow[t]{6}{*}{ Specific uniform } & 0 & 17.32 & 8 \\
\hline Canada & & 0 & 16.45 & 8 \\
\hline Mauritius & & 0 & 9.25 & 3 \\
\hline South Korea & & 0 & 17.41 & 3 \\
\hline USA & & 0 & 17.43 & 8 \\
\hline Uruguay & & 0 & 15.53 & 4 \\
\hline India & \multirow[t]{2}{*}{ Specific tiered } & 0 & 5.68 & 1 \\
\hline Brazil 2009 & & 0 & 15.40 & 1 \\
\hline France & \multirow[t]{6}{*}{ Mixed uniform } & $89.0 \%$ & 12.38 & 3 \\
\hline Germany & & $41.6 \%$ & 14.67 & 3 \\
\hline Malaysia & & $25.1 \%$ & 12.82 & 5 \\
\hline Mexico 2010-2012 & & $76.0 \%$ & 5.97 & 3 \\
\hline Netherlands & & $26.3 \%$ & 14.69 & 6 \\
\hline UK & & $43.2 \%$ & 16.20 & 8 \\
\hline Brazil 2012 & \multirow[t]{2}{*}{ Mixed tiered } & $22.1 \%$ & 15.71 & 1 \\
\hline China & & $94.1 \%$ & 17.11 & 3 \\
\hline Thailand & \multirow{2}{*}{$\begin{array}{l}\text { Ad valorem } \\
\text { uniform }\end{array}$} & $100 \%$ & 11.16 & 5 \\
\hline Mexico 2006-2008 & & $100 \%$ & 7.17 & 3 \\
\hline Bangladesh & Ad valorem tiered & $100 \%$ & 10.11 & 2 \\
\hline
\end{tabular}

Table 2 Summary statistics, $n=78$

\begin{tabular}{|c|c|c|}
\hline Dependent variable & Mean & SE \\
\hline Number of cigarettes per day & 13.560 & 0.919 \\
\hline Log form consumption & 2.559 & 0.073 \\
\hline Independent dummy variables & \multicolumn{2}{|c|}{ Number of country-years (\%) } \\
\hline Tiered & \multicolumn{2}{|l|}{$8(10)$} \\
\hline If USA, Canada or India & \multicolumn{2}{|l|}{$17(22)$} \\
\hline If in European Union & \multicolumn{2}{|l|}{$20(26)$} \\
\hline If HICs & \multicolumn{2}{|l|}{$47(60)$} \\
\hline Independent variable, continuous & Mean & SE \\
\hline$\%$ of ad valorem among excises & 36.431 & 0.099 \\
\hline Taxes & 2.978 & 0.578 \\
\hline Log form taxes & 0.627 & 0.184 \\
\hline GDP per capita in 10 thousands & 2.795 & 0.340 \\
\hline Log form GDP & 9.834 & 0.164 \\
\hline$\%$ Unemployment & 5.399 & 0.488 \\
\hline$\%$ Female & 50.242 & 0.229 \\
\hline$\%$ Population $15+$ & 78.130 & 1.317 \\
\hline
\end{tabular}

Statistics were adjusted for correlations within country over years. Tax structure shares in this sample are as the following: $44 \%$ had a specific uniform structure, $3 \%$ had a specific tiered structure, $36 \%$ had a mixed uniform structure, $5 \%$ had a mixed tiered structure, $10 \%$ had an ad valorem tax structure and $3 \%$ had an ad valorem tiered structure.

GDP, gross domestic product; HIC, high-income country.

taxes among total excise taxes, average cigarette consumption per day and the number of ITC survey waves used in the analyses. This table further illustrates that cigarette consumption in Mexico decreased from 7.17 sticks per day under an ad valorem uniform structure to 5.97 sticks per day under a mixed uniform structure, suggesting that a switch to more reliance on specific taxes may be associated with decreased cigarette consumption. In Brazil, cigarette consumption slightly increased from 15.4 per day to 15.71 per day after a change from a specific tiered to a mixed tiered structure.

Summary statistics after adjusting intertemporal correlations are reported in table 2 . The analytical sample consists of 78 country-year observations. On average, smokers smoked 14 cigarettes (around two-thirds of a 20 -stick pack) per day. Tiered structures represent $10 \%$ of the entire sample. The average share of ad valorem taxes among total excise tax was $36.4 \%$. Countries that allow local governments to differentiate taxes (ie, USA, Canada and India) account for $22 \%$ of the sample. EU countries that had a mixed structure under EU law took up $26 \%$ of the sample. HICs in total account for $60 \%$ of the sample. The average cigarette excise tax rates were $\$ 3$ on a 20 -stick pack.

Table 3 shows regression results from estimating the association between tax structure measures and cigarette consumption. Without controlling for the HIC dummy and average taxes (column1), a change from a specific to an ad valorem structure was associated with an $11 \%(\mathrm{p} \leq 0.05)$ higher cigarette consumption, whereas a change from a uniform to a tiered structure was associated with a $65.2 \%(\mathrm{p} \leq 0.001)$ higher cigarette consumption. These association estimates became smaller when the HIC dummy and average taxes were included as additional controls. When controlling for both the HIC dummy and average taxes (column 4), a change from a specific to an ad valorem structure was associated with a $5.8 \%(\mathrm{p} \leq 0.05)$ higher cigarette consumption, whereas a change from a uniform to a tiered structure was 
Table 3 The association between tax structure and cigarette consumption $(n=78)$

\begin{tabular}{lllll}
\hline & Model 1 & Model 2 & Model 3 & Model 4 \\
\hline & $\beta(\mathrm{SE})$ & $\beta(\mathrm{SE})$ & $\beta$ (SE) & $\beta(\mathrm{SE})$ \\
\% of ad valorem among excises & $0.111^{* *}(0.048)$ & $0.096^{*}(0.038)$ & $0.085^{*}(0.040)$ & $0.058^{*}(0.029)$ \\
Tiered & $0.652^{* * *}(0.194)$ & $0.575^{* * *}(0.136)$ & $0.440^{*}(0.185)$ & $0.343^{* *}(0.117)$ \\
Income & $0.430^{* * *}(0.105)$ & $0.319^{* *}(0.093)$ & $0.411^{* * *}(0.097)$ & $0.277^{* *}(0.092)$ \\
Average taxes & - & - & $-0.119^{* *}(0.040)$ & $-0.125^{* *}(0.043)$ \\
HIC dummy & No & Yes & No & Yes \\
\hline
\end{tabular}

Regressions also adjusted for dummies for European Union (EU) and for having local taxes, proportions of adults and gender, year fixed effects and unemployment rate. ${ }^{*} \mathrm{P} \leq 0.05 ;{ }^{* *} \mathrm{P} \leq 0.01 ;{ }^{* * *} \mathrm{P} \leq 0.001$.

HIC, high-income country.

associated with a $34.3 \%(\mathrm{p} \leq 0.01)$ higher cigarette consumption. The income elasticity estimates show that a $10 \%$ increase in GDP per capita was associated with a $3 \%-4 \%$ increase $(p \leq 0.001)$ in cigarette consumption. The tax elasticity estimates suggest that a $10 \%$ increase in taxes was associated with a $1 \%$ decrease $(\mathrm{p} \leq 0.01)$ in cigarette consumption.

Table 4 shows results for HICs and LMICs, respectively. A change from a specific to an ad valorem structure was associated with a $3.8 \%(p \leq 0.05)$ higher cigarette consumption in HICs. In addition, a change from a uniform to a tiered structure was associated with a $43.7 \%(\mathrm{p} \leq 0.05)$ higher cigarette consumption in LMICs. However, the share of ad valorem taxes in total excise was not significantly associated with cigarette consumption in LMICs.

\section{DISCUSSION AND CONCLUSION}

This study shows that complicated tax structures, particularly tiered structures, are associated with 34\%-65\% higher cigarette consumption among smokers. In addition, a greater share of ad valorem component among total excise taxed is also positively associated with cigarette consumption (6\%-11\%). These findings indicate that the effectiveness of increasing taxes in decreasing cigarette demand may be undermined by complicated tax structures that deviate from a specific uniform one. Given the very limited evidence on the association between tax structures and cigarette consumption, findings of this study provide much needed evidence to fill a knowledge gap.

During the study period, Mexico switched from an ad valorem uniform to a mixed uniform structure in 2009 and Brazil changed from a specific tiered to a mixed tiered system in 2012. ${ }^{4}$ The descriptive statistics showed that cigarette consumption in Mexico decreased from 7.17 sticks per day under an ad valorem uniform structure to 5.97 sticks per day under a mixed uniform structure, while cigarette consumption in Brazil slightly increased from 15.4 to 15.71 sticks per

Table 4 The association between tax structure and cigarette consumption, HIC versus LMICs, model 1

\begin{tabular}{lll}
\hline & HICs $(\mathrm{n}=47)$ & LMICs $(\mathrm{n}=31)$ \\
\hline & $\beta(\mathrm{SE})$ & $\beta$ (SE) \\
\% of ad valorem among excises & $0.038^{*}(0.017)$ & $-0.338(0.301)$ \\
Tiered & - & $0.437^{*}(0.194)$ \\
Income & $0.052(0.118)$ & $0.137(0.206)$ \\
\hline
\end{tabular}

Regressions also adjusted for proportions of adults and gender, year fixed effects and unemployment rate. HIC regression additionally adjusted for the European Union (EU) dummy.

${ }^{*} \mathrm{P} \leq 0.05$.

HIC, high-income country; LMIC, low/middle-income country. day after a change from a specific tiered to a mixed tiered structure. These changes are consistent with existing evidence that more reliance on ad valorem taxes (conversely less reliance on specific taxes) is associated with lower average prices and greater price variability that may lead to tax avoidance behaviours and undermine the effects of increasing taxes in reducing smoking. ${ }^{10}$

Regression results further provide evidence that complicated tax structures departing from a specific uniform one are associated with higher cigarette consumption. These findings are consistent with previous literature showing the associations of complicated tax structures with greater price variability and lower average prices. ${ }^{45}$ Greater price variability indicates that smokers have more opportunities to engage in tax avoidance by switching to cheaper products as taxes increase. Low average prices are a direct sign that taxes are not high enough to promote smokers to quit or prevent non-users from smoking cigarettes. Both scenarios could lead to higher cigarette consumption.

Furthermore, our results shed light on how tax structures may ultimately influence cigarette consumption. First, we found that tiered structures have the most pronounced positive association with cigarette consumption, regardless of the share of the ad valorem or specific component in taxes. This finding is consistent with our previous study where we found that tiered structures have a sizeable association with increased price variability, compared with uniform ones. The association between tiered structure and price variability was also greater than the association between the shares of specific or ad valorem components and price variability. The combined evidence indicates that tiered structures may pose the greatest threat to the effectiveness of tax increases in reducing smoking.

We found that a larger share of ad valorem taxes was associated with higher cigarette consumption. However, this association was moderate and became smaller when average taxes were controlled for. This may be because ad valorem taxes adjust simultaneously with increasing prices or product values and thus may offset their own influences on increasing price variability, particularly in countries with high inflation. If the government could not raise specific taxes frequent enough to keep pace with inflation, ad valorem taxes may have the advantage through automatically adjusting tax levels with inflation. As a result, we only found a moderate association between ad valorem tax shares and cigarette consumption.

Stratified analyses further support the above reasoning by showing that ad valorem tax shares were not significantly associated with cigarette consumption in LMICs where inflation is more common than in HICs. In LMICs, only a tiered structure was significantly associated with higher cigarette consumption. In HICs, although a greater share of ad valorem taxes was 
associated with higher cigarette consumption, we could not assess the association between a tiered structure and cigarette consumption because none of the HICs in the sample imposed a tiered structure.

There are several limitations of this study. The data consist of 78 observations from 17 countries, and therefore cannot represent all countries. Only two countries changed tax structures during the study period, precluding an examination of the causal impact of tax structures on consumption. Tiered structures were only seen for LMICs in the study sample and thus the results pertaining to tiered structures may not be generalisable. In addition, we could not assess the six tax structures jointly because observations for certain structure types were limited. We also could not control for time-varying tobacco control environment due to lack of data. Consumption was measured using aggregated self-reports and may contain self-report errors. The accuracy of cigarette consumption reports may also vary by countries. Finally, as many factors may influence consumption, our approach may not be free from omitted variable biases. Future studies should also explore the association between tax structures and smoking prevalence, which cannot be comprehensively studied using the ITC project data.

Nonetheless, this study extends the existing literature on the consequences of complicated tax structures by offering the first evidence on how these structures are associated with cigarette consumption using regression analyses. Our findings have several policy implications. The WHO FCTC's recommendation of simplifying tax structures may increase the effectiveness of taxes in reducing cigarette consumption. Tiered structures showed the most pronounced association with higher price variability and consumption, and thus should be the focus area to simplify a tax structure. Our results provide mixed recommendations for ad valorem structures. On the one hand, in LMICs where inflation is high and mechanisms to raise specific taxes are lacking, ad valorem tax structures may have advantages in raising taxes or prices. On the other hand, in HICs where taxes can be frequently adjusted, ad

\section{What this paper adds}

- Our study provides important empirical evidence of a relationship between tax structure and cigarette consumption. We find that a change from a specific to an ad valorem structure is associated with an $11 \%$ higher cigarette consumption. In addition, a change from uniform to tiered structure is associated with a $34 \%-65 \%$ higher cigarette consumption.

- Complicated tax structures are associated with greater price variability and lower price levels, which may undermine the effectiveness of increasing taxes in reducing smoking.

- To the best of our knowledge, no existing studies have analysed the association between complicated tax structures and cigarette consumption using regression analyses.

- Tiered structures are associated with higher cigarette consumption in low/middle- income countries.

- A higher reliance on ad valorem taxes is associated with higher cigarette consumption, particularly in high-income countries.

- The WHO Framework Convention on Tobacco Control's recommendation of simplifying tax structures may increase the effectiveness of taxes in reducing cigarette consumption. valorem taxes may be associated with higher price variability and consumption. Thus, a switch to specific taxes may increase the effectiveness of increasing taxes in reducing smoking.

Correction notice This article has been corrected since it was published Online First. Data values were accidentally interchanged in two separate sentences. Additional funding details have also been added.

Contributors CS and HML conducted the analyses and wrote the manuscript. All authors contributed to study design and reports interpretation. The findings and conclusions in this article are those of the authors.

Funding CS is funded by 1K99AA024810 (NIAAA). The earlier data cleaning work was funded by 1P01CA138389-05 (RJOC). The Waves 1-8 of the ITC-4 Country Survey were supported by Roswell Park Transdisciplinary Tobacco Use Research Center (grants R01 CA 100362 and P50 CA111236), the National Cancer Institute of the USA (R01 CA090955 and P01 CA138389), Robert Wood Johnson Foundation (045734), Canadian Institutes of Health Research (MOP57897, MOP-79551 and MOP-115016), Commonwealth Department of Health and Aging (AU Waves 1 and 2 only), Canadian Tobacco Control Research Initiative (014578), National Health and Medical Research Council of Australia (265903, 450110, 1005922), and Cancer Research UK (C312/A3726, C312/A6465, C321/ A11039, C25586/A19540). The Waves 1-6 of the ITC Netherlands Surveys were supported by The Netherlands Organisation for Health Research and Development (ZonMw; 70000001, 121010008). The SILNE Project is funded by the European Commission through FP7 HEALTH-F3-2011-278273. The Waves 1-3 of the ITC Germany Survey were supported by German Federal Ministry of Health, Dieter Mennekes-Umweltstiftung, and Germany Cancer Research Center (DKFZ). The Waves 1-3 of the ITC France Survey were supported by Observatoire français des drogues et des toxicomanies (OFDT), Institut national de prevention et d'education pour la sante (INPES), and Institut nationale du cancer (INCa). The Waves 1-3 of the ITC Korea Survey were supported by grants from the US National Cancer Institute (R01 CA125116), the Roswell Park Transdisciplinary Tobacco Use Research Center (P50 CA111236), the Korean Ministry of Health and Welfare, and the Korean National Cancer Center (0731040-1). The Waves 1-6 of the ITC Mexico Survey were supported by the Mexican Consejo Nacional de Ciencia y Tecnología (Salud-2007-C01-70032), Bloomberg Global Initiative-International Union Against Tuberculosis and Lung Disease (IUATLD), and the Roswell Park Transdisciplinary Tobacco Use Research Center from the National Cancer Institute at the National Institutes of Health (P50 CA111236). The Waves 1 and 2 of the ITC Brazil Survey were supported by the Brazilian Ministry of Health, National Cancer Institute José Alencar Gomes da Silva (INCA), Brazilian Ministry of Justice, National Secretariat for Drug Policy (SENAD), and the Canadian Institutes of Health Research (115016). The Waves 1-4 of the ITC Uruguay Survey were supported by Roswell Park Transdisciplinary Tobacco Use Research Center (grant P50 CA111236) and the US National Cancer Institute (P01 CA138389), International Development Research Centre (IDRC), and Canadian Institutes of Health Research (115016). The Waves 1-3 of the ITC Mauritius Survey were supported by the International Development Research Centre (Waves 1 and 2), the Canadian Institutes of Health Research (115016), and partially supported by the World Lung Foundation (Wave 3). The Waves 1 and 2 of the Tobacco Control Project (TCP) India Survey were supported by grants from the US National Cancer Institute (P50 CA111236, P01 CA138389) and Canadian Institute of Health Research (79551, 115016, 118096). The Waves 1-3 of the ITC Bangladesh Survey were supported by the International Development Research Centre (IDRC grant 104831-003), the US National Cancer Institute (P01 CA138389), and Canadian Institutes for Health Research (79551, 115016). The Waves 1-4 of the ITC China Project were supported by grants from the US National Cancer Institute at the National Institutes of Health (R01 CA125116), the Roswell Park Transdisciplinary Tobacco Use Research Center (P50 CA111236), Canadian Institutes for Health Research (79551, 115016), and Chinese Center for Disease Control and Prevention. The Waves 1-5 of the ITC Thailand Survey and Waves 1-5 ITC Malaysia were supported by Roswell Park Transdisciplinary Tobacco Use Research Center (grant P50 CA111236) and the US National Cancer Institute (P01 CA138389), Canadian Institutes of Health Research (79551, 115016), ThaiHealth Promotion Foundation, and the Malaysian Ministry of Health. Additional support in preparing this paper was provided to University of Waterloo by the Canadian Institutes of Health Research (FDN-148477).

Competing interests None declared.

Patient consent Obtained.

Ethics approval Ethics clearances were received from Office of Research Ethics, University of Waterloo, Canada and from the respective country's internal review board.

Provenance and peer review Not commissioned; externally peer reviewed.

(c) Article author(s) (or their employer(s) unless otherwise stated in the text of the article) 2019. All rights reserved. No commercial use is permitted unless otherwise expressly granted. 


\section{REFERENCES}

1 Organization WH. WHO report on the global tobacco epidemic, 2015: raising taxes on tobacco, 2015.

2 Shang C, Chaloupka FJ, Zahra N, et al. The distribution of cigarette prices under different tax structures: findings from the International Tobacco Control Policy Evaluation (ITC) Project. Tob Control 2014;23(Suppl 1):i23-9.

3 Chaloupka FJ, Kostova D, Shang C. Cigarette excise tax structure and cigarette prices: evidence from the global adult tobacco survey and the U.S. National Adult Tobacco Survey. Nicotine Tob Res 2014;16(Suppl 1):S3-9.

4 Shang C, Chaloupka FJ, Fong GT, et al. The association between tax structure and cigarette price variability: findings from the ITC Project. Tob Control 2016;24(Suppl 3):iii88-iii93.

5 Chaloupka FP, Tauras R, Xu JA, et al. Cigarette excise taxation: the impact of tax structure on prices, revenues, and cigarette smoking: NBER, editor, 2010.
6 Treasury USDo. Alcohol, tobacco and excise tax on firearms and ammunition.

7 Organization WH. WHO technical manual on tobacco tax administration, 2010.

8 Liber AC, Ross H, Ratanachena S, et al. Cigarette price level and variation in five Southeast Asian countries. Tob Control 2015;24:e137-41.

9 Choi K, Hennrikus D, Forster J, et al. Use of price-minimizing strategies by smokers and their effects on subsequent smoking behaviors. Nicotine Tob Res 2012:14:864-70.

10 Husain MJ, Kostova D, Mbulo L, et al. Changes in cigarette prices, affordability, and brand-tier consumption after a tobacco tax increase in Thailand: evidence from the global adult tobacco surveys, 2009 and 2011. Prev Med 2017;105s:S4-S9.

11 Fong GT, Cummings KM, Borland R, et al. The conceptual framework of the International Tobacco Control (ITC) Policy Evaluation Project. Tob Control 2006;15(Suppl 3):iii3-iii11.

12 Organization WH. WHO report on the global tobacco epidemic, 2013.

13 WHO. Relationship between tax and price and global evidence. http://www.who.int/ tobacco/economics/2_3relationshipbetweentaxprice.pdf 